\title{
Incidence and risk factors of portomesenteric venous thrombosis after colorectal surgery for cancer in the elderly population
}

\author{
Michele Manigrasso ${ }^{1}$, Marco Milone ${ }^{1,2^{*}}$, Nunzio Velotti ${ }^{3}$, Sara Vertaldi ${ }^{1}$, Pietro Schettino ${ }^{1}$, Mario Musella ${ }^{3}$, \\ Giovanni Aprea ${ }^{1}$, Nicola Gennarelli ${ }^{1}$, Francesco Maione ${ }^{1}$, Giovanni Sarnelli ${ }^{1}$, Pietro Venetucci ${ }^{3}$, \\ Giovanni Domenico De Palma ${ }^{1}$ and Francesco Milone ${ }^{3}$
}

\begin{abstract}
Background: Although it is known that portomesenteric venous thrombosis (PMVT) is associated with total colectomy and proctocolectomy in young patients with inflammatory bowel disease, little is known about incidence and risk factors of PMVT among the elderly population undergoing colorectal surgery for cancer.

Methods: Data of elderly patients (> 70 years) undergoing surgery for colorectal cancer were retrospectively registered. The occurrence of PMVT was correlated with the patients' characteristics and operative variables. Data collected included age, sex, obesity, ASA score, tumor degree, type of surgical resection, surgical approach (laparoscopic or open), and duration of surgery (from skin incision to the application of dressings).
\end{abstract}

Results: A total of 137 patients > 70 years who underwent surgery for colorectal cancer and developed an acute intraabdominal process with suggestive symptoms, needing a CT scan, were included. Three of these patients (2.1\%) had portomesenteric venous thrombosis during the study period, which was proved with CT scan. There were no significant patients' characteristics or operative variables between patients with or without the occurrence of PMVT after surgery. Of interest, only operative time was significantly higher in patients with PMVT after surgery $(256 \pm 40$ vs $140 \pm 41, p<0.001)$.

Conclusions: PMVT as a cause of abdominal pain after colorectal surgery for cancer in the elderly population is uncommon. An index of suspicion for PMVT in an elderly postoperative colorectal cancer patient with sudden onset of abdominal pain must be maintained.

Keywords: Portomesenteric, Venous thrombosis, Colorectal, Surgery

\section{Background}

Portomesenteric venous thrombosis (PMVT) is an uncommon, potentially life-threatening, condition. Data about PMVT in broader surgical population are scarce. Incidence and risk factors for PMVT development after major abdominal surgery, in particular colon and rectal

\footnotetext{
*Correspondence: milone.marco.md@gmail.com

'Department of Clinical Medicine and Surgery, University "Federico II" of Naples, Naples, Italy

${ }^{2}$ Department of Gastroenterology, Endocrinology and Surgical Endoscopy, University of Naples "Federico II", Via Pansini 5, 80131 Naples, Italy Full list of author information is available at the end of the article
}

procedures, have been recently studied $[1,2]$. The incidence of postoperative PMVT has been reported to range from 2.8 to $9 \%$. Although it is known that splanchnic venous thrombosis is associated with total colectomy and proctocolectomy in young patients with inflammatory bowel disease [3-5], little is known about incidence and risk factors of PMVT among the elderly population undergoing colorectal surgery for cancer. The incidence of postoperative PMVT after colorectal surgery has been reported to range from 2.8 to $9 \%$. Factors reported to be associated with the development of PMVT include manipulation of mesenteric vessels,

(c) The Author(s). 2019 Open Access This article is distributed under the terms of the Creative Commons Attribution 4.0 International License (http://creativecommons.org/licenses/by/4.0/), which permits unrestricted use, distribution, and 
postoperative septic complications, and various underlying diseases.

The aim of this study is to evaluate the incidence of PMVT after colorectal surgery in the elderly as well as the presence of risk factors, presenting symptoms, and the treatment.

\section{Methods}

Data of patients collected during a 12-year period (from September 2002 to July 2014) with diagnosis of colorectal cancer were retrospectively reviewed. The inclusion criteria were patients $>70$ years who underwent surgical intervention and needed CT scan for the new onset of abdominal pain. CT scans were performed using a spiral CT scanner with intravenously administered contrast.

Our perioperative prophylaxis routinely included subcutaneous heparin administration and perioperative handling of antiplatelet drugs according to the current literature [6-9]. A complete coagulation profile was performed whenever a diagnosis of portomesenteric venous thrombosis was made. The coagulation profile included platelet count, thrombin time, antithrombin III, plasminogen, protein C, protein $\mathrm{S}$, homocysteine level, factor $\mathrm{V}$ Leiden mutation, and prothrombin G20210A mutation,

Data collected included age, sex, obesity, ASA score, tumoral stage, type of surgical resection, surgical approach (laparoscopic or open), and duration of surgery (from skin incision to the application of dressings).

The occurrence of portomesenteric venous thrombosis was correlated with the patients' characteristics and operative variables.

Statistical analysis was performed with SPSS 16.0. The Yates corrected $\chi^{2}$ test was used to evaluate differences in categorical variables, and the independent samples $t$ test was used to analyze continuous variables. To adjust for covariates and to make predictions, logistic regression model was used. Statistical significance was accepted when the $p$ value was less than 0.05 .

\section{Results}

A total of 137 patients $>70$ years who underwent surgery for colorectal cancer with a postoperative onset of symptoms suggestive of an acute intraabdominal process, who therefore needed a CT scan were identified.

Three of these patients (2.1\%) had portomesenteric venous thrombosis during the study period, which was proved with $\mathrm{CT}$ scan. In all three cases, splanchnic venous thrombosis could be identified by CT scan. In most cases, the main symptom was the new-onset of acute abdominal pain. Other signs and symptoms included fever in two patients, of which one presented an elevated white blood cell count, and nausea in one patient. The intercurrent time between surgery and the acute event was respectively 35,62 , and 80 days.
Patients' characteristics and operative variables of entire study population and of the patients with PMVT are respectively shown in Tables 1 and 2 .

Considering thrombosis risk factors, none of the three patients with PMVT had any alteration of coagulation profile.

All three patients recovered from the acute event, with no need for further surgical intervention. They have been discharged from the hospital with long-term systemic oral anticoagulation for a minimum of 6 months. In details, to all subjects were given intravenous fluids, prophylactic antibiotic therapy (3rd generation cephalosporin-ceftriaxone- $1 \mathrm{~g}$ e.v. twice daily) and low molecular weight heparin $(\mathrm{LMWH})$ therapy $(100 \mathrm{UI} / \mathrm{Kg}$ s.c. twice/day). A week later, 2 patients were given warfarin with a target PT INR value $\geq 2$. The other patient underwent percutaneous transhepatic thrombolysis and mechanical thrombectomy prior to starting warfarin with a target PT INR value $\geq 2$. In both cases, LMWH was stopped when PT INR reached values of INR $\geq 2$ [10]. All the three cases of PMVT were successfully resolved.

After a median follow-up of 24 months, all three patients had discontinued taking their oral anticoagulants but no cases of recurrent thrombotic events have been reported. During the follow-up period, no death was reported.

There were no significant patients' characteristics or operative variables between patients with or without the occurrence of PMVT after surgery. Of interest, only

Table 1 Patients characteristics and operative variables of the 137 patients with abdominal pain

\begin{tabular}{ll}
\hline Age (years) & $75.5 \pm 7.1$ \\
Male gender (pts) & $70(51 \%)$ \\
Obesity (pts) & $27(19.7 \%)$ \\
ASA score & \\
II & $61(44.5 \%)$ \\
III & $53(38.6 \%)$ \\
IV & $23(16.7 \%)$ \\
Tumor grade & \\
I & $36(26.2 \%)$ \\
II & $58(42.2 \%)$ \\
III & $29(21.1 \%)$ \\
IV & $14(10.2 \%)$ \\
Surgery (pts) & $25(18.2 \%)$ \\
Right colectomy & $78(56.9 \%)$ \\
Left colectomy & $23(16.7 \%)$ \\
Rectal resection & $11(8 \%)$ \\
Miles intervention & \\
Laparoscopy (pts) & $34(24.8 \%)$ \\
Operative time (min) & $143.3 \pm 44.8$ \\
\hline
\end{tabular}


Table 2 Patients with PMVT

\begin{tabular}{lllllllll}
\hline & Age & Sex & Obesity & ASA & Tumor grade & Surgery & Approach & Operative time \\
\hline Patient 1 & 75 & Male & No & $\|$ & III & Right colectomy & Open & 250 \\
Patient 2 & 77 & Female & NO & $\|$ & I & Miles & Open & 220 \\
Patient 3 & 82 & Male & Yes & \|\| & $\|$ & Rectal resection & Laparoscopic & 300 \\
\hline
\end{tabular}

operative time was significantly higher in the group of patients with PMVT after surgery (256 \pm 40 vs $140 \pm 41$, $p<0,001)$. After adjusting for patients' characteristics and operative variables in a multivariate logistic regression, operative time showed a clear trend toward a higher PMVT occurrence (OR $=4.7$ 95\% CI).

\section{Discussion}

Life-threatening complications caused by thrombosis of portomesenteric venous system have been recognized and treated since the end of nineteenth century [11-13].

Portomesenteric venous thrombosis is known to be a rare condition that occurs in association with many other precipitating factors, capable of producing a wide range of clinical problems. Among the most common causes, there are hepatocellular carcinoma, cirrhosis, pyophlebitis from bowel disease, and spontaneous thrombosis from hypercoagulable state [14-17].

In this study, no patients had risk factors for thrombosis. In addition, there are no laboratory-chemical parameters specifically designed to confirm PMVT.

However, it is important to underline that the analysis of hematic parameters of thrombosis represents only a superficial examination, and it is not possible to rule out severe coagulation disorders with just this test.

At the moment, many medical centers perform CT scan as the primary imaging modality in patients with acute abdominal pain. CT scan is remarkably useful to identify bowel perforation or obstruction, as well as venous thrombosis or arterial ischemia [18-21].

PMVT development after colorectal surgery has been recently studied. This surgical population can include many of the proposed PMVT risk factors.

Several conditions can be cause of PMVT after colorectal surgery: the type of procedure, intraoperative manipulation of mesenteric vessels, intraabdominal pressure created by a pneumoperitoneum, intraabdominal septic complications, inherited or acquired prothrombotic conditions [2].

In fact, patients suffering from IBDs and cancer have a higher risk for venous thrombotic events, and this risk is further increased by septic complications and surgery $[15,17]$.

As far as we know, this is the first multicentric institution series evaluating the incidence and risk factors of symptomatic PMVT in elderly patients, undergoing elective colorectal surgery for cancer, with both open and laparoscopic technique.
It is well known that less invasive approach reached in the last decades increased popularity in each surgical field and it is considered the best surgical approach to colorectal and gastric malignancy [22-32]: shorter recovery and hospitalization, lower postoperative pain, and a better cosmetic results comparing with the open surgery are the main advantages of this technique, even in the elderly population [33, 34].

On the other side, data about PMWT after laparoscopic procedures are scarce.

Up to now, only Allaix et al. [2] retrospectively analyzed 1069 consecutive laparoscopic colorectal resections for inflammatory bowel disease and colorectal cancer. $3.5 \%$ patients experienced symptomatic postoperative PMVT. Robinson et al. [1] retrospectively reviewed 1224 patients who underwent colorectal surgery for carcinoma, IBD, or diverticulitis. Three percent of them were diagnosed with PMVT. Remzi et al. [35] retrospectively reviewed 702 patients undergoing total proctocolectomy and ileal pouch anal anastomosis for ulcerative colitis by an open approach. Symptomatic PMVT was observed in $6 \%$ of cases. Also Fichera et al. [3] published similar results in a retrospective analysis of 83 consecutive patients undergoing open total colectomy for IBD. They found a symptomatic PMVT in about 5\% of the patients studied. Finally, Antiel RM et al. [4] reviewed 366 pediatric patients who underwent colectomy for ulcerative colitis. Four percent were diagnosed with PMVT.

Thus, it is known that splanchnic venous thrombosis is associated with total colectomy and proctocolectomy in young patients with inflammatory bowel disease.

However, little is known about the incidence of PMVT after colorectal surgery in the elderly population. Mean age among current literature varies from 17.9 to 62 years $[2,4]$.

Speaking of incidence of PMVT, our observation confirms the findings of the other studies published in the literature; moreover, it extended these results to the elderly population.

We found symptomatic PMVT in $2.1 \%$ of the elderly (>70 years) population (mean age of $75.5 \pm 7.1$ years) after surgery. No death occurred during the 24-month follow-up period. Thus PMVT is not an uncommon cause of abdominal pain after colorectal surgery for cancer in the elderly population.

Risk factors for PMVT identified with univariate and multivariate analysis include only operative time. Of 
interest, laparoscopic colorectal resections were not associated with a higher risk of portomesenteric venous thrombosis occurrence.

Some limitations of this study have to be addressed. First of all, the study design, which is retrospective; another limitation is the small sample size, which could not be a guarantee of correlation between PMVT and surgical procedure; finally, the long period between discharge and PMVT that makes difficult the correlation between the intervention and the adverse event, although this is probably suggested by the lack of other risk factors.

\section{Conclusions}

PMVT is a complication of colorectal surgery, especially in the elderly population. Of our 137 patients, only three of them were symptomatic and present no specific symptoms.

CT scan was the best tool to investigate the presence of PMVT and confirmed in all cases the splanchnic vein thrombosis.

Although being this study a retrospective analysis, further studies are needed to confirm these results, an index of suspicion for PMVT in an elderly postoperative colorectal cancer patients with sudden onset of abdominal pain and fever must be maintained, especially in case a septic cause cannot be identified.

\section{Abbreviations}

$\mathrm{CT}$ : Computed tomography; IBD: Intestinal bowel disease; INR: International normalized ratio; LMWH: Low molecular weight heparin;

PMVT: Portomesenteric vein thrombosis; SMV: Spleno mesenteric vein

\section{Authors' contributions}

MM contributed to the conception, design, interpretation of the data, and drafting of the article; MM, MM, VN, VS, MM, AG, GN, MF, SG, and VP contributed acquisition, analysis, and interpretation of the data; DPGD and MF interpreted the data and critical revisions; MF made critical revisions and final approval. All the authors have read and approved the final manuscript.

\section{Funding}

The publication costs of this paper have been covered by the authors.

\section{Availability of data and materials}

All data are available and stored by the authors.

\section{Ethics approval and consent to participate}

This study does not require ethical approval because it is a retrospective case series.

\section{Consent for publication}

Not applicable.

\section{Competing interests}

The authors declare that they have no competing interests.

\section{Author details}

'Department of Clinical Medicine and Surgery, University "Federico II" of Naples, Naples, Italy. ${ }^{2}$ Department of Gastroenterology, Endocrinology and Surgical Endoscopy, University of Naples "Federico II", Via Pansini 5, 80131 Naples, Italy. ${ }^{3}$ Department of Advanced Biomedical Sciences, University "Federico II" of Naples, Naples, Italy.
Received: 8 August 2019 Accepted: 31 October 2019

Published online: 19 November 2019

\section{References}

1. Robinson KA, O'Donnell ME, Pearson D, Kriegshauser JS, Odeleye M, Kalkbrenner $\mathrm{K}$, et al. Portomesenteric venous thrombosis following major colon and rectal surgery: incidence and risk factors. Surg Endosc. 2015;29: 1071-9.

2. Allaix ME, Krane MK, Zoccali M, Umanskiy K, Hurst R, Fichera A. Postoperative portomesenteric venous thrombosis: lessons learned from 1,069 consecutive laparoscopic colorectal resections. World J Surg. 2014;38: 976-84

3. Fichera A, Cicchiello LA, Mendelson DS, Greenstein AJ, Heimann TM. Superior mesenteric vein thrombosis after colectomy for inflammatory bowel disease: a not uncommon cause of postoperative acute abdominal pain. Dis Colon Rectum. 2003;46:643-8.

4. Antiel RM, Hashim Y, Moir CR, Rodriguez V, Elraiyah T, Zarroug AE. Intraabdominal venous thrombosis after colectomy in pediatric patients with chronic ulcerative colitis: incidence, treatment, and outcomes. J Pediatr Surg. 2014;49:614-7.

5. Millan M, Hull TL, Hammel J, Remzi F. Portal vein thrombi after restorative proctocolectomy: serious complication without long-term sequelae. Dis Colon Rectum. 2007;50:1540-4

6. Samama CM. Perioperative venous thromboembolism prophylaxis: short review and recommendations. Ann Fr Anesth Reanim. 2008;27:S2-8.

7. Di Minno MND, Milone M, Mastronardi P, Ambrosino A, Di Minno A, Parolari A, et al. Perioperative handling of antiplatelet drugs. A critical appraisal. Curr Drug Targets. 2013;14:880-8.

8. Di Minno MN, Prisco D, Ruocco AL, Mastronardi P, Massa S, Di Minno G. Perioperative handling of patients on antiplatelet therapy with need for surgery. Intern Emerg Med. 2009;4:279-88.

9. Amato B, Compagna R, Rocca A, Bianco T, Milone M, Sivero L, et al. Fondaparinux vs warfarin for the treatment of unsuspected pulmonary embolism in cancer patients. Drug Des Devel Ther. 2016;23(10):2041-6.

10. Di Minno MN, Milone F, Milone M, laccarino V, Venetucci P, Lupoli R, et al. Endovascular thrombolysis in acute mesenteric vein thrombosis: a 3-year follow-up with the rate of short and long-term sequaelae in 32 patients. Thromb Res. 2010;126:295-8.

11. Elliot JW. The operative relief of gangrene of intestine due to occlusion of the mesenteric vessels. Ann Surg. 1895;21:9-23.

12. Ageno W, Riva N, Schulman S, Beyer-Westendorf J, Bang SM, Senzolo M, et al. Long-term clinical outcomes of splanchnic vein thrombosis: results of an international registry. JAMA Intern Med. 2015;175:1474-80.

13. Ageno W, Riva N, Schulman S, Bang SM, Sartori MT, Grandone E, et al. Antithrombotic treatment of splanchnic vein thrombosis: results of an international registry. Semin Thromb Hemost. 2014;40:99-105.

14. Cohen J, Edelman RR, Chopra S. Portal vein thrombosis: a review. Am J Med. 1992:92:173-82.

15. Valla DC, Condat B. Portal vein thrombosis in adults: pathophysiology, pathogenesis and management. J Hepatol. 2000:32:865-71.

16. Plemmons RM, Dooley DP, Longfield RN. Septic thromboplebitis of the portal vein (phlebitis): diagnosis and management in the modern era. Clin Infect Dis. 1995:21:1114-20.

17. Kumar S, Sarr MG, Kamath PS. Mesenteric venous thrombosis. N Engl J Med. 2001:345:1683-8.

18. Milone M, Di Minno MN, Musella M, Maietta P, laccarino V, Barone G, et al. Computed tomography findings of pneumatosis and portomesenteric venous gas in acute bowel ischemia. World J Gastroenterol. 2013:19:6579-84.

19. Oda S, Nakaura T, Utsunomiya D, Funama Y, Taguchi N, Imuta M, et al. Clinical potential of retrospective on-demand spectral analysis using duallayer spectral detector-computed tomography in ischemia complicating small-bowel obstruction. Emerg Radiol. 2017:24:431-4.

20. Levenson RB, Troy KM, Lee KS. Acute abdominal pain following optical colonoscopy: CT findings and clinical considerations. AJR Am J Roentgenol. 2016:207:W33-40

21. Sheen $\mathrm{CL}$, Lamparelli $\mathrm{H}$, Milne A. Clinical features, diagnosis and outcome of acute portal vein thrombosis. QJM. 2000;93:531-4.

22. Milone M, Fernandez LM, Musella M, Milone F. Safety and efficacy of minimally invasive video-assisted ablation of pilonidal sinus: a randomized clinical trial. JAMA Surg. 2016;151(6):547-53. 
23. Milone M, Elmore U, Musella M, Parise P, Zotti MC, Bracale U, Di Lauro K, Manigrasso M, Milone F, Rosati R. Safety and efficacy of laparoscopic wedge gastrectomy for large gastrointestinal stromal tumors. Eur J Surg Oncol. 2017:43(4):796-800.

24. Uccella S, Casarin J, Morosi C, Miraglia A, Candeloro I, Carollo S, et al. Hysterectomy for uteri weighing $\geq 1 \mathrm{~kg}$ : laparoscopic vs. open approach. J Minim Invasive Gynecol. 2015;22:S87.

25. Milone M, Manigrasso M, Elmore U, Maione F, Gennarelli N, Rondelli F, Velotti N, De Palma GD. Short- and long-term outcomes after transverse versus extended colectomy for transverse colon cancer. A systematic review and meta-analysis. Int J Color Dis. 2019;34(2):201-7.

26. Milone M, Manigrasso M, Burati M, Velotti N, Milone F, De Palma GD. Surgical resection for rectal cancer. Is laparoscopic surgery as successful as open approach? A systematic review with meta-analysis. PLoS One. 2018; 13(10):e0204887.

27. Milone $M$, Angelini $P$, Berardi $G$, Burati $M$, et al. Intracorporeal versus extracorporeal anastomosis after laparoscopic left colectomy for splenic flexure cancer: results from a multi-institutional audit on 181 consecutive patients. Surg Endosc. 2018;32(8):3467-73.

28. Golombos DM, Chughtai B, Trinh QD, Thomas D, Mao J, Te A, et al. Minimally invasive vs open nephrectomy in the modern era: does approach matter? World J Urol. 2017;35:1557-68.

29. Conzo G, Musella M, Corcione F, De Palma M, Avenia N, Milone M, Della Pietra C, Palazzo A, Parmeggiani D, Pasquali D, Sinisi AA, Santini L. Laparoscopic treatment of pheochromocytomas smaller or larger than 6 $\mathrm{cm}$. A clinical retrospective study on 44 patients. Laparoscopic adrenalectomy for pheochromocytoma. Ann Ital Chir. 2013;84(4):417-22.

30. Milone M, Elmore U, Di Salvo E, Delrio P, Bucci L, Ferulano GP, et al. Intracorporeal versus extracorporeal anastomosis. Results from a multicentre comparative study on 512 right-sided colorectal cancers. Surg Endosc. 2015; 29:2314-20

31. Milone M, Manigrasso M, Velotti N, Torino S, Vozza A, Sarnelli G, Aprea G, Maione F, Gennarelli N, Musella M, De Palma GD. Completeness of total mesorectum excision of laparoscopic versus robotic surgery: a review with a meta-analysis. Int J Color Dis. 2019;34(6):983-91.

32. Milone M, Elmore U, Vignali A, Gennarelli N, Manigrasso M, Burati M, Milone F, De Palma GD, Delrio P, Rosati R. Recovery after intracorporeal anastomosis in laparoscopic right hemicolectomy: a systematic review and meta-analysis. Langenbeck's Arch Surg. 2018;403(1):1-10.

33. Fujii S, Tsukamoto M, Fukushima Y, Shimada R, Okamoto K, Tsuchiya T, et al. Systematic review of laparoscopic vs open surgery for colorectal cancer in elderly patients. World J Gastrointest Oncol. 2016;8:573-82.

34. Uccella S, Bonzini M, Palomba S, Fanfani F, Malzoni M, Ceccaroni M, et al. Laparoscopic vs. open treatment of endometrial cancer in the elderly and very elderly: an age-stratified multicenter study on 1606 women. Gynecol Oncol. 2016;141:211-7.

35. Remzi FH, Fazio WW, Oncel M, Baker ME, Church JM, Ooi BS, et al. Portal vein thrombi after restorative proctocolectomy. Surgery. 2002;132:655-62.

\section{Publisher's Note}

Springer Nature remains neutral with regard to jurisdictional claims in published maps and institutional affiliations.

Ready to submit your research? Choose BMC and benefit from:
- fast, convenient online submission
- thorough peer review by experienced researchers in your field
- rapid publication on acceptance
- support for research data, including large and complex data types
- gold Open Access which fosters wider collaboration and increased citations
- maximum visibility for your research: over 100M website views per year
At BMC, research is always in progress.
Learn more biomedcentral.com/submissions

